\title{
Incidental findings: expect to find the unexpected
}

$\mathrm{W}$

hen a CT scan for a fractured pelvis turns up a kidney abnormality, doctors must decide what this information means - and whether to tell the patient. Incidental findings and the ethical quandaries surrounding their disclosure are increasingly common due to improved medical technology, the US Presidential Commission for the Study of Bioethical Issues revealed in a recent report.

It states that while some accidental discoveries can be lifesaving, others are merely the cause of "uncertainty and distress without any corresponding improvement in health." Of particular concern are abdominal computed tomography (CT) scans, $30 \%-35 \%$ of which lead to incidental findings, according to the report.

"We should think about this ahead of time and have a plan," says Dr. Daniel Sulmasy, a member of the commission and a professor of medicine and ethics at the University of Chicago in Illinois. "It's a pretty simple message."

The commission recommends that clinicians and researchers describe possible incidental findings to patients before conducting tests and procedures, and agree upon which findings will and will not be disclosed. The Dec. 12, 2013 report also calls on professional groups to develop guidelines for handling incidental discoveries. However, the recommendations stop short of addressing circumstances in which a doctor or researcher shouldn't disclose an incidental finding.

Practically, "we would overburden the system and not have time to actually treat anybody if we were going to have a lengthy discussion about every single possible test that comes back with something a little out of normal range," says Sulmasy. Conducting additional follow-up tests or procedures can be risky and costly, and some knowledge creates more emotional turmoil than medical benefit.

Carol Krucoff, who collapsed from

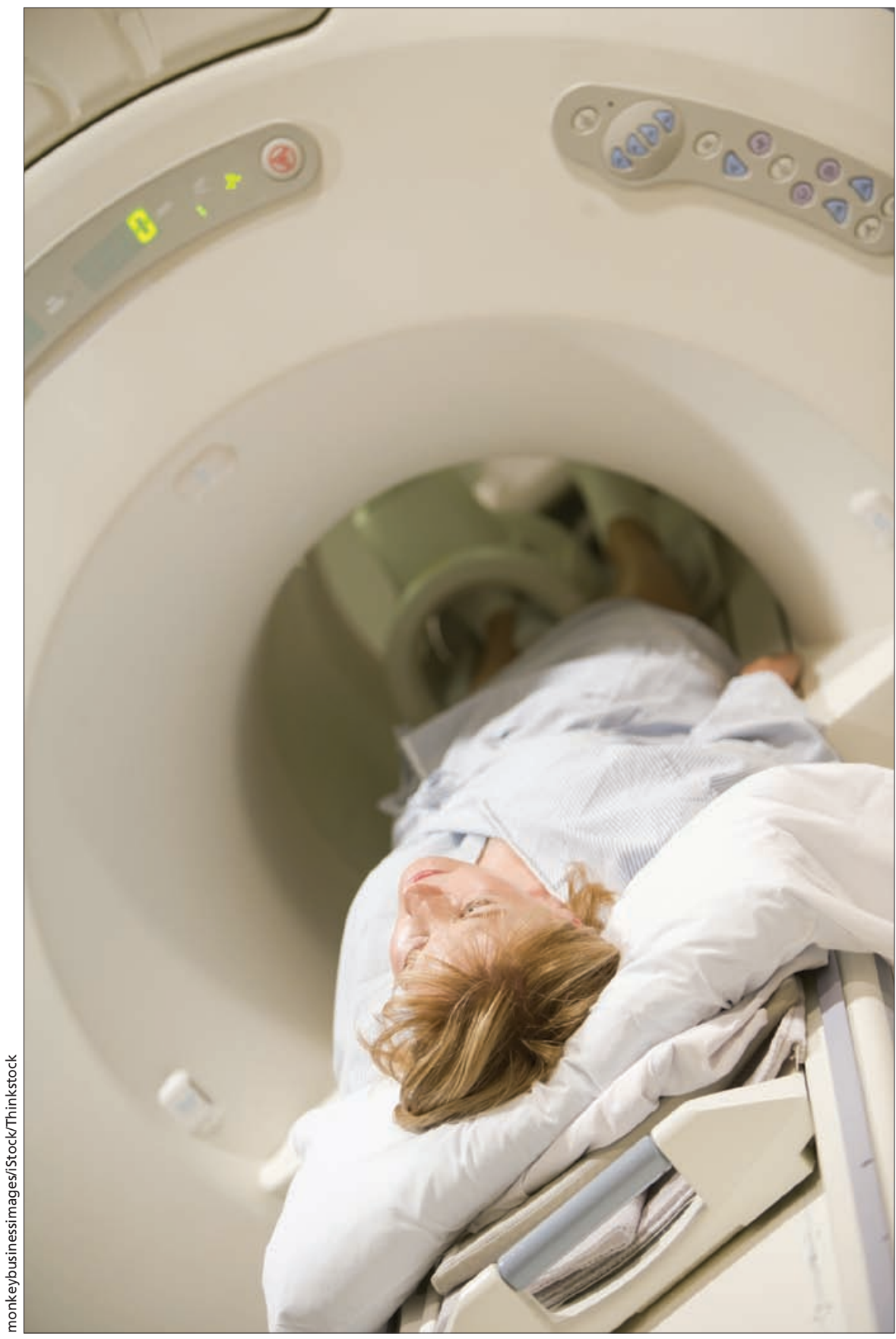

The likelihood of encountering incidental findings using medical imaging is high, but few of these findings have serious health consequences, say bioethics experts.

overhydration while running a marathon, is a case in point. During an evaluation, her emergency care team discovered a small brain tumour. She has since spent nine anxious years watching for any change. "I try to completely forget that I even have this little brain tumour," she says, but adds that she's still glad she knows.

Physicians must weigh both sides, 
says Carolyn Ells, a bioethicist and associate professor of medicine at McGill University in Montréal, Quebec. "We don't want to have someone label themselves sick or ill when they're not."

She says exceptions to the rule of disclosing all the information that a patient wants to know may arise when findings are transient or indicate a condition for which there is no effective treatment.
However, proposed changes to a Canadian policy statement on the responsible conduct of research assert that the onus is on researchers to justify such exceptions to their ethics boards on a case-by-case basis.

Ultimately, the basis of any action should be an evidence-based analysis, says Ells. "It is important, as much as possible, to find evidence to help guide to what extent we share information with patients."

The bioethics commission report echoes her call, urging more research into the type, frequency, costs, benefits and preferences of those involved when it comes to sharing incidental findings. - Kierra Jones, CMAJ

CMAJ 2014. DOI:10.1503/cmaj.109-4695 